\title{
LEPIDOPTERAN SURVEY OF GRAND TETON NATIONAL PARK
}

\author{
K. Bagdonas \\ T. McGann \\ M. Rehg \\ M. Harrington \\ S. Blanche \\ Department of Zoology and Physiology \\ University of Wyoming.
}

\section{Objectives}

Lepidopterans play an integral role in high altitude ecosystems of the Rocky Mountain region as larval herbivores and, more importantly as pollinating adults. Lepidopterans also constitute a major food source for many other invertebrates and vertebrates inhabiting these areas. However, very little is known about the lepidopteran fauna of Wyoming, particularly the Heterocera(moths), and especially in the National Parks. It has therefore been impossible to accurately assess the degree to which lepidopterans affect the ecosystems.

Initiated in 1979-1980, a base line study of the macro-lepidopteran species and the formulation of a synoptic list of the lepidopteran species inhabiting Grand Teton National Park was continued and expanded in 1980-1981. When this study and list are completed, we will have data directly applicable to making economic, and ecological, and evolutionary designations for the majority of the macro lepidopteran species inhabiting the area.

Related studies in Rocky Mountain National Park and elsewhere in Colorado, Wyoming and Utah (Bagdonas, 1976; Bagdonas, et al. 1977a, 1977b, 1977c, 1977d, 1978a, 1978b, 1978c, 1979a, 1979b, 1979c, 1979d, 1979e, 1979f, 1979g; Bagdonas, 1980a, 1980b; Bagdonas, et al. 1980c, 1980d) have indicated many lepidopteran species in the $\overline{R o c} \overline{k y}$ Mountains are survivors of the Pleistocene glaciations. The data obtained from these "relict" or "marker" species can be used in the ageing and the determination of the rates of evolution within the high altitude ecosystems of Grand Teton National Park. This information combined with:photographs and text will be used for a book on the butterflies and moths of the Park. If our proposed expansion of this project into Yellowstone National Park is funded, this book will incorporate the lepidopteran faunas inhabiting both of these National Parks. 
Methods

The macro-lepidopteran fauna of Grand Teton National Park was studied from May 27 through August 23, 1980. Research on the diurnal species was conducted throughout the Park while nocturnal species were monitored at 16 locations with habitats representative of the entire Park. Furthermore, micro-moths were collected during the month of August. These specimens were given to $\mathrm{Dr}$. R. Lavigne and M. Pough, of the University of Wyoming, to assist in their research of several of the microheteroceran families of Wyoming. Collecting procedures were the same as in 1979 (Bagdonas, et al. 1979f) with the addition of "sugar baiting" to attract moths in the cottonwood stands along the Snake River.

A successful effort was made to sample those areas of the Park which were not studied in 1979 and to continue the monitoring of those areas which were. Work was conducted in areas that are frequently visited by humans as well as "remote" areas at elevations from 6750 to 11590 feet.

\section{Results}

Although hampered frequently by poor weather conditions, the $1980 \mathrm{field}$ season still proved to be very productive. Table 1 provides information regarding the number of species recorded for each family of Rhopalocera (butterflies) in Grand Teton National Park, and a brief record of the research done on these species. To date, we have recorded 81 species from 7 families. For $79 \%$ of those species recorded, we have data from both 1979 and 1980. We feel that $78 \%$ of the species have been adequately researched to complete the proposed objectives. Furthermore, during 1980 , we produced book quality, "in the field" photographs of $88 \%$ of the butterflies known to inhabit Grand Teton National Park. We were unable to photograph the remaining $12 \%$ for a variety of reasons, including alternate year life cycles and failure to observe photograph quality specimens. However, we should be able to finish the photography of these species during the summer of 1981.

Table 2 provides a comparison of our success collecting nocturnal moths and important contributing factors. We were, in part, able to offset the detrimental effect of the cool, wet weather with an increased familiarity of the area gained in 1979. The reduction in total numbers caught during June and July of 1980 stem from our inability to operate as many stations as in 1979. In June this was due to poor weather while in July, we spent a week in Laramie attending the 7 th Annual International Xerces Society meetings. The low figures for the number of specimens caught per night per station reflect the incorporation of the mixed-light trap station at the U.W.-N.P.S. Research Center. This station, especially in 1980, was not productive. The total number of moths collected however, rose from 1730 in 1979 to 2099 in 1980. Furthermore, we added 55 new species to our list bringing the current total to 150 .

In 1980, did not see any specimens of the rare sphingid moth, Proserpinus clarkiae, discovered in Wyoming and Grand Teton National Park 


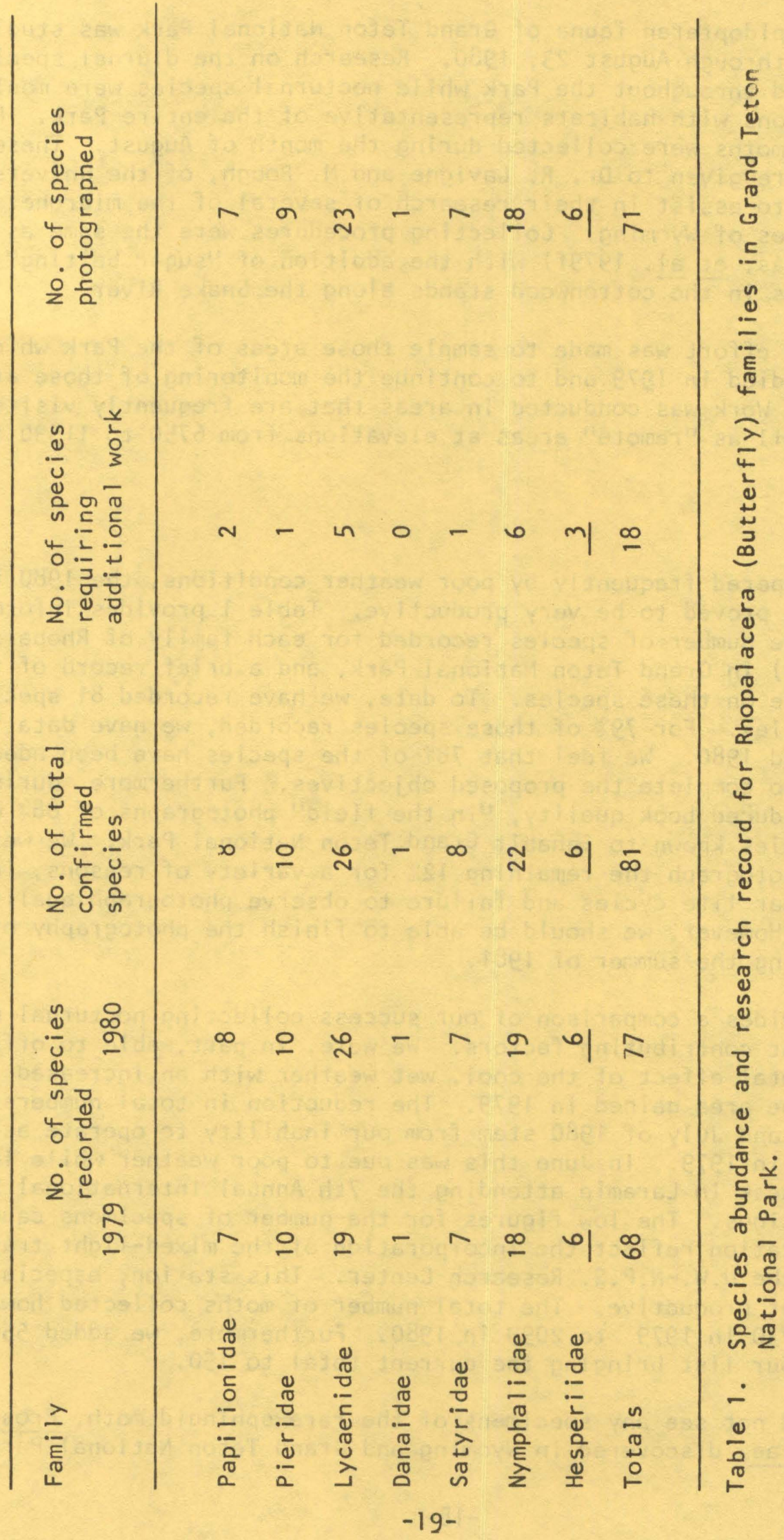




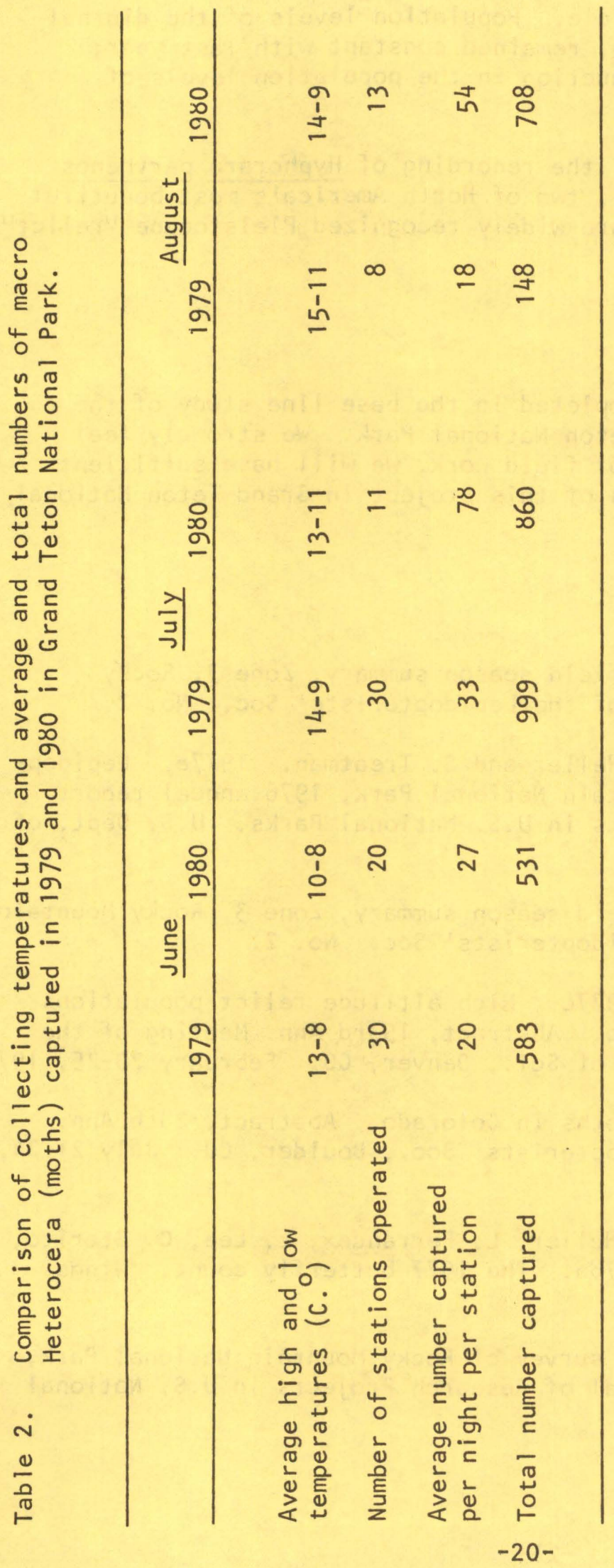


last year by our group. This information strengthens our belief that it has a 2-year reproductive cycle. Population levels of the diurnal silk moth, Hemiluca eglanterina, remained constant with last year; however, we noted a drastic reduction in the population levels of Hemiluca hera.

of special importance, in 1980, the recording of Hyphorara parthenos and Paractia lapponica yarrowi , two of North America's most beautiful and rarest tiger moths. Both are widely recognized Pleistocene "relict" species.

\section{Conclusion}

Work, on schedule, has been completed in the base line study of the macro-lepidopterans of Grand Teton National Park. We strongly feel that with one additional year of field work, we wili have sufficient data to complete all objectives of this project in Grand Teton National Park.

\section{Literature Cited}

Bagdonas, K. 1976. The 1975 field season summary, Zone 3, Rocky Mountain Division. News of the Lepidopterists' Soc. No. 2.

Bagdonas, K., L. Draegner, I. Heller and S. Treatman. 1977a. Lepidoptera survey of Rocly Mountain National Park, 1976 annual report. Manual of Research Projects in U.S. National Parks. U.S. Dept. of the Int.

- 1977b. The 1976 field season summary, Zone 3, Rocky Mountain Division, News of the Lepidopterists' Soc. No. 2.

Bagdonas, K. and I. Heller. 1977c. High altitude relict populations of Lepidoptera in Colorado. Abstract, 153rd Ann. Meeting of the Amer. Assoc. for the Adv. of Sci., Denver, Co. February 20-25, 1977.

Bagdonas, K. 1977d. Relict moths in Colorado. Abstract, 28th Ann. Meeting of the Int. Lepidopterists' Soc., Boulder, CO. July 21-24, 1977.

Bagdonas, K., T. Clifford, I. Heller, L. Ferrandex, L. Lee, C. Starito, R. Muzzi, L. Filippe. 1978a. The 1977 butterfly count. Wings 11 \& $12: 6-7$.

- 1978b. Lepidoptera survey of Rocky Mountain National Park, 1977 Annual Report. Manual of Research Projects in U.S. National Parks. U.S. Dept. Int. 
1978c. The 1977 field season summary, Zone 3, Rocky Mountain Division. News of the Lepidopterists' Soc. No. 2.

Bagdonas, K., T. Clifford, M. Harrington, S. Hill, J. Hogue, T. McGann, T. Meeks, L. Snyder, C. Sorg, C. Wilkinson, E. Williams. 1979a. The 1978 butterfly count. Wings 6(2):5-6.

Bagdonas, K., T. Clifford, M. Harrington, S. Hill, J. Hogue, T. McGann, T. Meeks, K. Ramsey, M. Regh, M. Schwind, L. Snyder, C. Sorg, M. Trieste, C. Wilkinson, E. Williams. 1979b. The 1978 field season summary, Zone 3, Rocky Mountain Division. News of the Lepidopterists' Soc. No. 2.

1979c. Lepidoptera survey of Rocky Mountain National Park, 1978 annual report. Manual of Research Projects in U.S. National Parks. U.S. Dept. Int.

Bagdonas, K. 1979d. The butterflies and moths of Rocky Mountain National Park: a new book. Abstract, 6 th Ann. Meeting of the Int. Xerces Soc., Baltimore, MD, May 18-20, 1979.

Bagdonas, K. and M. Harrington. 1979e. Color variant adaptations in moths in Crouse Canyon, Utah. Abstract, 30th Ann. Meeting of the Int. Lepidopterists; Soc., Fairbanks, Alaska, June 28-July 1, 1979. News of the Lepidopterists' Soc. 5:6.

Bagdonas, K., t. McGann, M. Rehg, S. Blanche, A. Houston, K. Wilkinson, 1979f. Lepidopteran survey of Grand Teton National Park. U.W.N.P.S. Research Center Third Annual Report: 7-11.

Bagdonas, K., S. Blanche, J. Carlisle, T. Clifford, M. Harrington, A. Houston, T. McGann, M. Regh, A. Tebaldi, C. Wilkinson. 1979g. The 1979 butterfly count. (Accepted for publication, Wings 7:2)

Bagdonas, K., 1980a. Important new lepidopteran records for Colorado and Wyoming. Abstract, 31 st Ann. Meeting of the Int. Lepidopterists' Soc., Gainsvill, FL. June 19-21, 1980.

Bagdonas, K. 1980. The rediscovery of Euproserpinus wiesti, a prairie Sphinx moth. Abstract, 7 th Ann. Meeting of the Int. Xerces Soc., Laramie, WY. July $18-20,1980$

Bagdonas, K., W. Bagdonas, S. Blanche, C. Campbe 11, M. Crone, B. Davis, D. Geiss, M. Harrington, I. Heller, B. Lowry, T. McGann, F. Melius, A. Overstreet, M. Rehg, R. Skinner. 1980c. The 1980 butterfly count. (Accepted for publication in Wings).

- 1980d. The Butterflies and Moths of Rocky Mountain National Park and Surrounding Area. Rocky Mountain Nature Association (In press, Lepidoptera Research Foundation, Inc., Publishers; scheduled for distribution, May, 1981). 


\section{Acknowledgements}

We would once again like to extend our sincere thanks to the UW-NPS Research Center staff, particularly Dr. Kenneth Diem, Director for assistance with the logistics of our project over the past two years. We also wish to thank Mr. Robert Wood of the National Park Service for his assistance with our permits. 